\title{
SOBRE LA NECESIDAD DE ARMONIZAR LAS LEYES URBANÍSTICAS DE LAS COMUNIDADES AUTÓNOMAS
}

\author{
Abel Enguita Puebla (Dr. Arquitecto - Profesor Ad Honorem DUyOT)
}

\section{Introducción}

Como consecuencia de la aplicación del Art. 148.3 de la Constitución Española, que atribuye la competencia exclusiva en materia de "ordenación del territorio, urbanismo y vivienda" a las Comunidades Autónomas, éstas se han ido dotando de leyes específicas en esta materia, que han ido introduciendo -respecto de una legislación estatal común- numerosas disparidades, tanto en relación con los instrumentos de planeamiento y gestión del urbanismo y la ordenación del territorio, como en relación con las cargas y cesiones gratuitas impuestas a los propietarios.

En consecuencia, en materia de urbanismo y ordenación del territorio, no sólo se ha producido una ruptura de la unidad de mercado en los sectores afectados, sino una indirecta desigualdad en los derechos de la propiedad ligados al suelo. Por otra parte -a diferencia de otros países de la Unión Europea - en España el Estado ha ido perdiendo la visión y control global de las transformaciones_del territorio,con la consiguiente pérdida de eficacia en la planificación de las grandes infraestructuras nacionales, consumos de energía y aplicación de políticas de sostenibilidad diversas.

Así en efecto, en Dinamarca, en aplicación de su Ley del Planeamiento de 2002 después de cada Nueva elección al Folketing (Parlamento) el Ministro de Medio Ambiente debe presentar un informe sobre el planeamiento nacional al Comité para el Medio Ambiente y el Planeamiento Regional del Folketing ( Art.2). Adicionalmente el Ministro de Medio Ambiente "para asegurar la protección de los intereses nacionales, incluyendo asegurar la calidad del planeamiento...puede establecer normas reguladoras del uso de la autoridad garantizada por esta Ley y el contenido del planeamiento de acuerdo con esta Ley" ( Art.3 ).

En los Países Bajos, la Ley de Planeamiento Espacial de 2006 introduce un sistema de planeamiento espacial al nivel nacional, de carácter indicativo, mediante las denominadas Decisiones Clave de Planeamiento (Planologische Kernbeslissing). La primera, de las tres clases de Decisiones Clave de Planeamiento que diferencia la Ley, se denomina Esquemas de Estructura Nacional, y se refieren a desarrollos espaciales de escala nacional de medio y largo plazo. Un ejemplo es el Documento de Política Nacional sobre Planeamiento Espacial de 2004.

En Alemania, el sistema de planeamiento está descentralizado como en España, la Federación no cuenta con un instrumento de planeamiento espacial comprehensivo legalmente vinculante, pero en su lugar la Federación establece los principios de " Raumordnung", que son las líneas directrices fundamentales para todo el planeamiento y la política espaciales en Alemania. Mediante la nueva Ley Federal de Planeamiento Espacial (Raumordnunsgesetz) la Federación está autorizada para establecer los conceptos directores (Leitbilder) del desarrollo espacial en cooperación con los estados federados. 
Por otra parte la citada Ley Federal establece la obligatoriedad de elaborar un informe regular sobre el estado del planeamiento espacial, que se publica con intervalos regulares, generalmente cada cuatro años.

Finalmente, en el Reino Unido, en marzo de 2012 se publicaba el National Planning Policy Framework ( Marco para la Política Nacional de Planeamiento ) que establece las políticas del Gobierno en materia de planeamiento y como han de ser aplicadas. Proporciona un marco dentro del cual las autoridades locales pueden elaborar sus planes locales distintivos, que reflejen las necesidades y prioridades de sus respectivas comunidades.

En este contexto europeo, el texto refundido de la Ley del Suelo estatal de España de 2008 introducía en su Art.15.5 la siguiente norma:

"Las Administraciones competentes en materia de ordenación y ejecución urbanística deberán elevar al órgano que corresponda de entre sus órganos colegiados de gobierno, con la periodicidad mínima que fije la legislación en la materia, un informe de seguimiento de la actividad de ejecución urbanística de su competencia, que deberá considerar al menos la sostenibilidad ambiental y económica a que se refiere este artículo. Los Municipios estarán obligados al informe a que se refiere el párrafo anterior cuando lo disponga la legislación en la materia y, al menos, cuando deban tener una Junta de Gobierno Local "

De este texto se deduce que se impone a las Administraciones Autonómicas la obligación de controlar y coordinar el desarrollo urbanístico de sus municipios, mediante un seguimiento de este que garantice su sostenibilidad ambiental y económica, pero dichas Administraciones Autonómicas no asumen la obligación equivalente de trasladar a la Administración del Estado ningún tipo de informe regular equivalente que permita garantizar dicha sostenibilidad ambiental y económica a la escala del territorio nacional.

El Art. 150.3 de la Constitución establece sin embargo que:

"El Estado podrá dictar Leyes que establezcan los principios necesarios para armonizar las disposiciones normativas de las Comunidades Autónomas aún en el caso de materias atribuídas a la competencia de éstas, cuando así lo exija el interés general. Corresponde a las Cortes Generales, por mayoría absoluta de cada Cámara, la apreciación de esta necesidad".

Dado que actualmente se dan la motivación y condiciones necesarias para la armonización de las leyes urbanísticas de las Comunidades Autónomas, se considera necesario que dicha armonización sea abordada, abarcando al menos el contenido que se propone a continuación.

\section{Propuestas para la armonización de las leyes urbanísticas de las Comunidades Autónomas}

1) Presentación obligatoria por el Gobierno de un informe regular (cuatrienal) a las Cortes, sobre estado de la ordenación urbanística y territorial en el país.

Esta práctica asentada ya hace tiempo en países como Alemania o los Países Bajos -en los que dichos informes se presentan al Parlamento cada cuatro años- 
permite el seguimiento continuado de los procesos de transformación del territorio que derivan de la dinámica de las áreas urbanas y su valoración desde una perspectiva global. A partir de la misma, el Gobierno puede establecer políticas o líneas directrices de escala nacional, que orienten los planeamientos regionales a la consecución de una ordenación territorial y urbanística del país, más racional y sostenible. Adicionalmente, dicha perspectiva constituye una base fundamental de referencia al efecto de la planificación más eficiente de las grandes infraestructuras de escala nacional, directamente ligadas a las demandas generadas en las áreas urbanas. En consecuencia de todo lo anterior y con base en la obligatoriedad para las administraciones competentes de informar periódicamente del seguimiento de la actividad urbanística, que introduce la Ley del Suelo Estatal de 2008 citada, se abre la posibilidad de regular un proceso informativo de abajo-arriba, que permita la elaboración del informe regular con gran facilidad, con la frecuencia cuatrienal considerada.

2) Coordinación del planeamiento regional:

En aras a garantizar la coherencia a escala nacional de la ordenación del territorio, llevada a cabo a través de planeamientos de escala regional, se hace necesario armonizar tanto su contenido normativo, como documental. Asímismo deben establecerse procedimientos que aseguren la coordinación de planeamientos entre regiones adyacentes que prevengan la solución de continuidades naturales y favorezcan la obtención de economías de escala o la mayor funcionalidad y reducción de costes en el proyecto de infraestructuras suprarregionales.

2.1) Contenido normativo básico, común en los planes de ámbito regional.

Los planes de ámbito regional deberían hacer diferenciación entre dos tipos de determinaciones:

a) Determinaciones con repercusión suprarregional. Estas determinaciones deberían desarrollar/aplicar las políticas o líneas directrices de escala nacional en vigor. Adicionalmente deberá asegurarse su compatibilidad y coherencia con las determinaciones correspondientes de las regiones limítrofes.

b) Determinaciones de carácter interno regional. Desarrollarían aquellas políticas específicas, propias de cada ámbito regional, cuyo contenido carece de repercusión externa.

2.2) Delimitación de ámbitos subregionales de planeamiento y ámbitos transfronterizos.

Con el fin de fomentar la consecución de lógicas y necesarias economías de escala -en la implantación y posterior mantenimiento de infraestructuras- y una mayor racionalidad en la administración territorial, se debería inducir la agrupación de municipios, a efectos de planeamiento, en ámbitos subregionales.Tales agrupaciones podrían establecerse: 
a) Por iniciativa de municipios colindantes, integrados en áreas territoriales homogéneas que compartan los mismos intereses. En base a esta consideración, podrán establecerse agrupaciones "transfronterizas" de municipios, que afecten a comunidades autónomas adyacentes.

b) Mediante el establecimiento, por la administración autonómica correspondiente, de umbrales mínimos de población para la delimitación de los ámbitos de planeamiento urbanístico general.

El papel del Estado en este proceso se concretaría en el establecimiento de los criterios generales a aplicar para las agrupaciones, en coherencia con las políticas de escala nacional establecidas para la orientación de los planeamientos regionales.

\section{Armonización básica de los planes generales municipales y parciales:}

A partir del reestablecimiento de una misma tipología de clasificación del suelo común para todas las CC.AA - se debería armonizar el contenido básico o esencial de dichos instrumentos de planeamiento. Asímismo se debería establecer, con carácter general, cuáles han de considerarse, en los planes generales, las determinaciones de carácter estructurante.

\section{Armonización básica de las cesiones obligatorias y gratuitas:}

Cesiones para reservas dotacionales: Las diferentes leyes urbanísticas autonómicas actualmente vigentes, fijan -empleando diferentes criterios para establecer la base de referencia para los cálculos- categorías y estándares distintos para cuantificar las cesiones obligatorias y gratuitas. El resultado es que -según la autonomía de que se trate- la carga económica que suponen dichas cesiones para el promotor de una misma actuación varía, sin que haya una razón lógica fundamentada. Parece más lógico por el contrario que con carácter general, y con base en las características de la población beneficiaria, se estableciesen los tipos de dotaciones para las que se puede reclamar una cesión gratuita de suelo (o superficie construída, en aplicación del concepto de complejo inmobiliario establecido en el art. 17.4 del RDL 2/2008 de la Ley del Suelo Estatal T.R.) y se fijasen los estándares a aplicar para cuantificar la magnitud de la cesión.

\section{Armonización de los sistemas de ejecución:}

Complementariamente a la armonización de los instrumentos de planeamiento, se considera necesario armonizar los sistemas de ejecución en cuanto se refiere tanto a las clases aplicables, como a los procedimientos y requisitos regulados para su aplicación. 


\section{Unificación de la documentación requerida en los diversos instrumentos de planeamiento y sistemas de ejecución:}

Una de las tendencias más recientes en Europa relativas al urbanismo es la orientada a la digitalización generalizada de la información de los documentos de planeamiento y gestión urbanísticos, con el fin de facilitar el acceso a los mismos de los usuarios y ciudadanos en general y reducción de costes. El caso paradigmático es el de los Países Bajos, con la puesta en práctica desde el 2010, tras la aprobación de la nueva Ley de Planeamiento Espacial, de un plan global que requiere la normalización y aplicación generalizada a todo el país, tanto de los contenidos, como de los soportes gráficos, códigos representativos y en suma todos los elementos integrantes de los documentos de planeamiento y gestión. Con esta referencia, extrema, se considera necesario abordar en España, al menos, la unificación al nivel nacional, de los documentos exigibles en la tramitación de los planes y los sistemas de ejecución. 